\title{
Goitre and iodine deficiency in Afghanistan: a case-control study
}

\author{
Odile Oberlin ${ }^{1}$, Emmanuelle Plantin-Carrenard $^{2}$, Odile Rigal $^{3}$ and Caroline Wilkinson ${ }^{1} *$ \\ ${ }^{1}$ Action Contre la Faim, 4 rue Niepce, 75014 Paris, France \\ ${ }^{2}$ Centre Hospitalier Jacques Coeur, 145 avenue François Mitterand, 18000 Bourges, France \\ ${ }^{3}$ Hopital Robert Debré, 48 boulevard Sérurier, 75019 Paris, France
}

(Received 10 November 2004 - Revised 14 July 2005 - Accepted 17 July 2005)

\begin{abstract}
I deficiency is the leading cause of preventable mental retardation. A number of surveys in Afghanistan show goitre prevalence rates more than $20 \%$ amongst children and women. Access to iodised salt remains low, with disparate coverage by region, despite the recent implementation of a national salt iodisation programme. The objectives were to identify whether the presence of goitre is a satisfactory marker of I deficiency and to examine the relationship between goitre and thyroid function. A case-control study was carried out in children and women of childbearing age, stratified on the presence of goitre. Adequate levels of urinary I were observed in $6.8 \%$ of all the subjects, and amongst the subjects without goitre, this figure was only $9 \%$. The presence of goitre was significantly associated with severe urinary I deficiency; however, the difference between the cases and controls was not as great as expected. An association between the presence of goitre and elevated thyroid-stimulating hormone (TSH) levels was observed, but $14 \%$ of the children without palpable goitre also showed abnormal TSH levels. Given that the majority of subjects showed some degree of I deficiency and that children without goitre may have elevated TSH levels, the absence of goitre is an insufficient indicator to determine adequate I status. The risk of subsequent development of goitre, in the currently non-goitre population, is elevated. This suggests that short-term I supplementation should be considered independently of the presence of goitre or urinary I level, until the access to and consumption of iodised salt is generalised.
\end{abstract}

Iodine deficiency: Goitre: Afghanistan: Thyroid-stimulating hormone: Thiocyanate

Brain damage is the single most important preventable effect among the I-deficiency disorders (IDD) (Pharoah \& Connolly, 1987; World Health Organization, 1993; Hetzel, 2000; Bernal, 2002). This mental deficiency has an immediate effect on a child's learning capacity, women's health, the quality of life of communities and economic productivity. I deficiency in women of childbearing age is of concern, because of the effects on the developing fetus and the risk of both physical and mental developmental problems (Fierro-Benitez et al. 1988; Hollowell et al. 2005). IDD are amongst the cheapest of all disorders to prevent (Tonglet et al. 1992; Peterson et al. 1999).

In Afghanistan, the Hindukush mountain range, from the Northeast to the Southwest of the country, represents an endemic I-deficiency area. There are no national data for estimating clinical or biochemical prevalence of IDD in Afghanistan; however, a number of surveys, conducted during 2000-2002, showed goitre rates of between 20 and $63 \%$ amongst schoolaged children and women (Azizi, 2001; International Council for the Control of Iodine Deficiency Disorders, 2004).

A nutrition survey performed by the international humanitarian organisation Action Contre la Faim (ACF) in the Panshir Valley (Shamali plain) region of Afghanistan in March-April 2002 showed that amongst mothers of 929 children aged 6-59 months, 50.9\% presented with visible goitre. A similar survey undertaken in August 2002 found even higher rates of visible goitre amongst mothers $(63.7 \%)$
(United Nations Standing Committee on Nutrition, 2002a). These values are extremely high, since a prevalence of greater than $5 \%$ within a population is considered to be the threshold for determining a public health problem (World Health Organization, 1999).

Given such a high prevalence of goitre, the Afghan Ministry of Public Health and UNICEF have been making major efforts towards ensuring the availability of iodised salt in the country (Afghan Ministry of Public Health and UNICEF, 2003). This is a very long-term national salt iodisation programme, and I supplementation for women and children, in particularly affected areas, needs consideration before iodised salt becomes widely available and used in all regions of Afghanistan.

The objectives of the present study were to identify whether the presence of goitre is a satisfactory marker of I deficiency and to examine the relationship between goitre and thyroid function (these results would help to define the criteria for targeting for I supplementation). An additional objective was to explore the consequences of I deficiency on the health of women and the mental development of children.

\section{Subjects and methods}

Study period and area

The present study was conducted in the Gulbahar area at the border of the Parwan and Kapisa provinces, $80 \mathrm{~km}$ North of 
Kabul in Afghanistan. This area is $20 \mathrm{~km}$ away from the main access road from Kabul to the north of Afghanistan. It is a mountainous area, $1600 \mathrm{~m}$ above sea level and is densely populated, characterised by small villages of between twenty to fifty houses. There are three larger towns with shops and weekly markets in the area. Most of the inhabitants are subsistence farmers and are of the Tajik ethnic origin. The region has been marked by periods of violent conflict, with repeated migrations during the Soviet invasion (1979-89). Repeated bombings by the Taliban during the recent civilian war (1994-2001) again forced the population to take refuge in the nearby Panshir valley on several occasions.

The study was performed during October and November 2003 in four ACF nutrition centres, in neighbouring districts within the two provinces of Parwan and Kapisa. Cases and controls were children and women voluntarily recruited into the study after public announcements in the villages and in girls' schools. Controls were matched to cases by sex and by age group (5-year intervals) and as far as possible by area of residence. Cases and controls were excluded if they were beneficiaries of the ACF nutritional programmes.

\section{Thyroid status}

Clinical thyroid status was evaluated and goitre was assessed by the same observer $(\mathrm{O} . \mathrm{O}$.) and graded according to a modified WHO grading (grade 0 , no palpable or visible goitre; grade 1a, goitre palpable but not visible when the neck is fully extended; grade $1 b$, goitre palpable and visible only when the neck is fully extended; grade 2, goitre visible when the neck is in the normal position; World Health Organization, 1999).

Although ultrasonography would have provided a better and more reliable quantitative measurement of thyroid volume, the method chosen was the palpation method by a single operator for all subjects using the classification recommended by the International Council for the Control of Iodine Deficiency Disorders (World Health Organization, 1999). This choice was due to several operational constraints (cost of the instrument, training of the operator, lack of electricity, lack of normative values for thyroid volume in I-sufficient children and women in Afghanistan). In reality a large proportion of the children and women had clearly visible goitre.

\section{Clinical evaluation}

Height, weight and mid-upper-arm circumference were measured using standard techniques. Age was recorded using the mother's or the child's statements. The reported age was often only an estimation, with frequent discrepancies being observed between the reported age and the physical aspect (for instance, a boy who reported to be 9 years old still having his milk teeth). The high prevalence of chronic malnutrition (stunting) also adds to this confusion and age inaccuracies (United Nations Standing Committee on Nutrition, 2002a).

Women were questioned on their marital status and reproductive history, including the number of pregnancies, miscarriages and stillbirths, the number of living children and of children who had died before the age of 5 years and the cause of death.

Children were asked about their school attendance and their level. In Afghanistan, children start school at 6 years of age and the school system has twelve levels. Information about migration was also asked. Clinical examination included investigation of symptoms of hypothyroidism, blood pressure and pulse rate.

Cognitive function was evaluated in children over 5 years old. The first two tests were designed for an illiterate population and are scored according to age-specific standards (Bellis et al. 1998).

\section{Ravens Progressive Matrices test}

The Ravens Progressive Matrices test is based on the resolution of logical problems with partly truncated geometric drawings. Given six possibilities, the child has to choose which one is the best to complete each drawing. It measures the visual reasoning ability.

\section{Pegboard test}

The pegboard test is made up of a board with two rows of twenty-five holes. The child has $30 \mathrm{~s}$ to move as many wooden pegs as possible, in a precise order, into one of the rows and then to the other, first with the right hand, then with the left and then with both hands simultaneously. It measures the fine motor coordination and is often used as a global measure of intelligence quotient.

\section{Object assembly test}

An additional object assembly test (a type of jigsaw puzzle) from the Wechsler Intelligence Scale for Children (WISC III) was administered. It measures the part-whole reasoning, visual analysis and construction of objects.

The results of this set of three tests were allocated a fourscore performance rating ( 1 to 4 , median score being 3 ).

For the children who scored poorly or very poorly in this series of tests (score 1 or 2), a fourth test based on the identification of pictures of familiar objects was given, in order to discriminate between the levels of difficulty (between scores 1 and 2) the children faced. There is no standard scoring scale for this series of four tests applied together; it was a pragmatic choice to apply them in conjunction.

\section{Biology}

Filter paper blood spots were collected for the assay of thyroid-stimulating hormone (TSH). TSH was assayed by immunofluorimetry using an Autodelphia kit (Perkin-Elmer Life Sciences, Boston, MA, USA), in the Robert Debré hospital in Paris. TSH measurement was reported in whole blood units. The upper normal values of TSH of whole blood measured on filter paper is well known for newborns; however, the correlation between TSH levels of whole blood and TSH levels measured in plasma was not available from the literature or from the Robert Debré hospital laboratory. O. R. performed a correlation study on twenty-five blood samples of children seen in the endocrinology department over a period of 1 week. From these samples, both plasma and paper blood spots were used for the TSH assay. The corresponding correlation equation was $\mathrm{a}=2 \cdot 19 \mathrm{~b}+0.228$ (' $\mathrm{a}$ ' being plasma concentration and ' $b$ ' being paper blood spot 
concentration). Given the upper limit of normal plasma TSH values of $6.0 \mathrm{mU} / \mathrm{ml}$, the upper limit of normal values of TSH on paper blood spot was defined as $2.6 \mathrm{mU} / \mathrm{ml}$.

Urine samples were collected from children over 5 years and from women. Urinary I concentration was measured from a casual urine sample for pragmatic reasons, since accurate collection of $24 \mathrm{~h}$ urine samples was not possible in this context.

Urinary I levels were classified according to the joint criteria of WHO, UNICEF, and the International Council for the Control of Iodine Deficiency Disorders (World Health Organization, 1999). Deficiency was defined as being either severe $(<20 \mu \mathrm{g} / \mathrm{l})$, moderate $(20-50 \mu \mathrm{g} / \mathrm{l})$, or mild $(50-$ $100 \mu \mathrm{g} / \mathrm{l}$ ). No deficiency (normal level of I) was defined if the level was $>100 \mu \mathrm{g} / \mathrm{l}$ and excess was defined when the level was $>300 \mu \mathrm{g} / \mathrm{l}$.

Urinary I was measured at the biochemistry laboratory of Groupe hospitalier Pitié-Salpétrière in Paris (France), using a semi-quantitative colorimetric method using ferroin as a redox indicator by Plantin-Carrenard et al. (2004). This semi-quantitative method has good sensitivity and specificity to detect I deficiency, being respectively 91 and $93 \%$ (Plantin-Carrenard et al. 2004). The interference of other substances (such as thiocyanate) on this measure has been excluded by the concomitant use of a quantitative method in selected cases.

Urinary thiocyanate level was measured in the same laboratory for a large subgroup of subjects, using Pettigrew's colorimetric method (Pettigrew \& Fell, 1972).

\section{Salt test}

Subjects were asked to bring a sample of salt used for household cooking. The salt field test kits provided by UNICEF's Nutrition Section (Field Test for Iodated Salt; Peyman Tashkhis, Tehran, Iran) were used to determine the level of $I$ in the salt. One drop of this stabilised starch-based solution produces a blue-purple coloration, the intensity of which indicates the approximate I level above 15 parts per million. These kits were pre-tested on salt known to contain I and this colour change was observed.

\section{Statistical analyses}

Comparison between cases and controls was performed by Student's $t$ test for normally distributed data. Differences between two proportions were evaluated by $\chi^{2}$ analysis. A $P$ value less than 0.05 was considered statistically significant. The odds ratios with their CI were estimated by Woolf's method. All other statistical calculations were performed using Epi Info $^{\mathrm{TM}}$ software (Centers for Disease Control and Prevention, Atlanta, GA, USA).

\section{Results}

\section{Distribution of the population}

One hundred and forty individuals without goitre and 150 with goitre were involved in the present study. Two hundred and twenty-four children (110 boys and 114 girls) ranging from 1 month to 15 years old were assessed. Their mean age was 8.6 years (SD 0.25). Among the 106 children with visible or palpable goitre, fifty-six had grade 1a, twenty-three had grade $1 \mathrm{~b}$ and twenty-seven had grade 2 goitre.

Table 1 shows the distribution of the 224 assessed children according to age range, sex and presence of goitre. The mean age of children with goitre was older than the mean age of children without goitre (10.2 v. 7.2 years). This difference appears to be due to the small number of children with goitre in the age group of 5 years old or younger and does not apply to the older children.

More than half $(51 \%)$ of the children aged 6 years or over were attending school, in the levels 1 to 7 (median level of 3 ). The sample of women ( $n$ 66) had a mean age of 27.5 (range 16-40) years. Thirty-four had goitre; eleven were grade $1 \mathrm{a}$, five were grade $1 \mathrm{~b}$ and eighteen were grade 2 . The mean age of the thirty-two women without goitre was 29.3 years, this being slightly older than the mean age of the thirty-four women with visible or palpable goitre $(25.7$ years) $(P=0.02)$.

\section{Anthropometric evaluation}

BMI was calculated for fifty-five women (where both accurate height and weight measurements were available). Median BMI was 21.3 (SD 3.43 , range $16.8-32.9$ ) $\mathrm{kg} / \mathrm{m}^{2}$, with $71 \%$ of the women in the normal range $\left(18.5 \geq \mathrm{BMI}<25 \mathrm{~kg} / \mathrm{m}^{2}\right)$ and $20 \%$ in the underweight category $\left(\mathrm{BMI}<18.5 \mathrm{~kg} / \mathrm{m}^{2}\right.$ ). There was no association between the presence of goitre and BMI (data not shown).

The age reporting in children was too inaccurate to be able to estimate weight-for-age or height-for-age values. The analysis between anthropometric status and presence of goitre was, therefore, not performed for the sample of children.

Table 1. Distribution of the 224 children (110 boys and 114 girls) according to age range, goitre status and sex

\begin{tabular}{|c|c|c|c|c|c|c|c|}
\hline Age range (years) & $n$ & Goitre status & Total $(n)$ & Male $(n)$ & Female $(n)$ & Mean age (years) & $P$ \\
\hline \multirow[t]{2}{*}{$0-5$} & \multirow[t]{2}{*}{47} & With & 7 & 3 & 4 & $2 \cdot 5$ & \multirow[t]{2}{*}{$<0.01$} \\
\hline & & Without & 40 & 20 & 20 & $4 \cdot 6$ & \\
\hline \multirow[t]{2}{*}{$5 \cdot 1-10$} & \multirow[t]{2}{*}{95} & With & 44 & 19 & 25 & 8 & \multirow[t]{2}{*}{ NS } \\
\hline & & Without & 51 & 26 & 20 & $8 \cdot 5$ & \\
\hline \multirow[t]{2}{*}{$10 \cdot 1-15$} & \multirow[t]{2}{*}{87} & With & 55 & 29 & 26 & $12 \cdot 1$ & \multirow[t]{2}{*}{ NS } \\
\hline & & Without & 32 & 13 & 19 & $12 \cdot 3$ & \\
\hline \multirow[t]{2}{*}{ Total children* } & \multirow[t]{2}{*}{224} & With & 106 & 51 & 55 & & \\
\hline & & Without & 118 & 59 & 59 & & \\
\hline
\end{tabular}

\footnotetext{
* The mean age of the 224 children was 8.6 years.
} 


\section{Cognitive development evaluation}

One hundred and nineteen children over 5 years were tested for cognitive development. Twenty-eight of the fifty-four children aged $5 \cdot 1$ to 10 years and forty of the sixty-five children aged $10 \cdot 1$ to 15 years had goitre.

The children had no difficulties in understanding the tasks required of them for the tests.

All measures were substantially lower in these Afghan children compared with the standards of the tests. No differences in developmental status were found between boys and girls.

There was no difference in the psychometric tests according to thyroid status. Using a 1 to 4 scale score, the mean global score was 2.88 (SD 1.4) for children without goitre and 2.91 (SD 1.6) for children with goitre.

\section{Pregnancy and children}

Amongst the sixty-six women, forty-seven were married, three were widows and one was separated. For these fifty-one women, the number of pregnancies per women varied from 0 to 12 (mean 5.2), the number of live children at birth ranged from 0 to 12 (mean 4.9). The number of children who died before, during or within a few days after delivery ranged from 0 to 5 (mean $0 \cdot 2$ ). The number of children who died before the age of 5 years ranged from 0 to 5 (mean 1.2). The number of living children varied from 0 to 9 (mean 3.7).

Of these fifty-one women, twenty-three had goitre and twenty-eight did not. The women without goitre had a higher mean number of pregnancies than those with goitre $(5.8 v .4 .4)$; this difference was not statistically significant $(P=0 \cdot 18)$. The number of children who died before, during or within a few days after delivery was similar in both groups (0.25 and 0.22). The number of live children after birth was also greater for women without goitre than for those with goitre $(5.5 v .4 \cdot 2 ; P=0.15)$. The numbers of children who died before 5 years of age (respectively 1.4 and 1) and of alive children at the age of 5 years $(4.1 v .3 .3)$ were not statistically different in both groups.

\section{Biochemical findings}

Data on urinary I levels are shown in Table 2.

Urinary I levels were assessed for 250 individuals (188 children over 5 years and sixty-two women). Amongst the children, 103 had goitre and eighty-five did not. In the group of children without goitre ( $n$ 85), only $10.6 \%$ had normal I levels, whilst $89.5 \%$ had I deficiency; $42.3 \%$ of which was severe, $40 \%$ moderate and $7.1 \%$ mild. In the group of children with goitre ( $n$ 103), 52.4\% showed severe I deficiency, $35 \%$ moderate and $6.8 \%$ mild. Only $5.8 \%$ showed no deficiency.

Amongst the sixty-two women, thirty had goitre and thirtytwo did not. Despite the absence of goitre in the group of thirty-two evaluated women, $31.2 \%$ were classified as having severe I deficiency, $53.1 \%$ moderate and $9.4 \%$ mild. Only $6.2 \%$ of the women had normal levels of urinary I. In the group of thirty women with goitre, $50 \%$ showed severe I deficiency, $43.3 \%$ moderate and $6.7 \%$ mild. None of the women with goitre had a normal level of urinary I.

In both children and women, there was a non-significant relationship between goitre and urinary I level considering the classification of I deficiency in all four classes; this was the case, even when these data for children and women were pooled together.

Considering the whole population (women and children) and dividing the urinary I level into two classes (severe I deficiency $v$. no or mild or moderate deficiency), the presence of goitre was significantly associated with severe I deficiency (odds ratio 1.6 (95\% CI 1, 2.75); $P<0.05$; Table 3 ).

Separating the children and women into two separate groups showed a trend but a non-significant relationship between goitre and severe I deficiency. Amongst the children without goitre, $42 \%$ had severe I deficiency (defined by I $<20 \mu \mathrm{g} / \mathrm{l})$, whereas $52 \%$ of the children with goitre had such a severe I deficiency $(P=0 \cdot 16)$. Amongst the women without goitre, $31 \%$ had severe I deficiency, whereas this was the case for $44 \%$ of the women with goitre (Table 3).

Table 2. Urinary iodine level according to the presence of a goitre

\begin{tabular}{|c|c|c|c|c|c|c|c|}
\hline & \multirow[b]{2}{*}{ Urinary I level $(\mu \mathrm{g} / \mathrm{l})$} & \multicolumn{2}{|c|}{ No goitre } & \multicolumn{2}{|c|}{ Goitre } & \multirow[b]{2}{*}{ Total $(n)$} & \multirow[b]{2}{*}{$P$} \\
\hline & & $n$ & $\%$ & $n$ & $\%$ & & \\
\hline \multicolumn{8}{|l|}{ All } \\
\hline No deficiency & $>100$ & 11 & $9 \cdot 4$ & 6 & 4.5 & 17 & \\
\hline Mild & $50-100$ & 9 & $7 \cdot 7$ & 9 & $6 \cdot 7$ & 18 & \\
\hline Moderate & $20-50$ & 51 & 43.5 & 49 & $36 \cdot 8$ & 100 & \\
\hline Severe & $<20$ & 46 & $39 \cdot 3$ & 69 & $51 \cdot 8$ & 115 & \\
\hline $\begin{array}{l}\text { Total } \\
\text { Children }\end{array}$ & & 117 & & 113 & & 250 & 0.45 \\
\hline No deficiency & $>100$ & 9 & $10 \cdot 5$ & 6 & $5 \cdot 8$ & 15 & \\
\hline Mild & $50-100$ & 6 & $7 \cdot 0$ & 7 & $6 \cdot 8$ & 13 & \\
\hline Moderate & $20-50$ & 34 & $40 \cdot 0$ & 36 & $35 \cdot 0$ & 70 & \\
\hline Severe & $<20$ & 36 & $42 \cdot 3$ & 54 & $52 \cdot 4$ & 90 & \\
\hline Total & & 85 & & 103 & & 188 & 0.45 \\
\hline \multicolumn{8}{|l|}{ Women } \\
\hline No deficiency & $>100$ & 2 & $6 \cdot 2$ & 0 & 0.0 & 2 & \\
\hline Mild & $50-100$ & 3 & 9.4 & 2 & $6 \cdot 7$ & 5 & \\
\hline Moderate & $20-50$ & 17 & $53 \cdot 1$ & 13 & $43 \cdot 3$ & 30 & \\
\hline Severe & $<20$ & 10 & 31.2 & 15 & $50 \cdot 0$ & 25 & \\
\hline Total & & 32 & & 30 & & 62 & 0.29 \\
\hline
\end{tabular}


Table 3. Presence of a goitre in severe iodine deficiency

(Odds ratios with $95 \%$ confidence intervals)

\begin{tabular}{|c|c|c|c|c|c|c|c|c|c|}
\hline & \multirow[b]{2}{*}{ Urinary I level ( $\mu \mathrm{g} / \mathrm{l})$} & \multirow[b]{2}{*}{$n$} & \multicolumn{2}{|c|}{ No goitre } & \multicolumn{2}{|c|}{ Goitre } & \multirow[b]{2}{*}{ OR } & \multirow[b]{2}{*}{$95 \% \mathrm{Cl}$} & \multirow[b]{2}{*}{$P$} \\
\hline & & & $n$ & $\%$ & $n$ & $\%$ & & & \\
\hline All & & & 117 & & 133 & & 1.66 & $1,2 \cdot 75$ & 0.047 \\
\hline Mild, moderate or no deficiency & $\geq 20$ & 135 & 71 & 61 & 64 & 48 & & & \\
\hline Severe I deficiency & $<20$ & 115 & 46 & 39 & 69 & 52 & & & \\
\hline Children & & & 85 & & 103 & & 1.50 & $0 \cdot 84,2 \cdot 68$ & $0 \cdot 16$ \\
\hline Mild, moderate or no deficiency & $\geq 20$ & 98 & 49 & 58 & 49 & 48 & & & \\
\hline Severe I deficiency & $<20$ & 90 & 36 & 42 & 54 & 52 & & & \\
\hline Women & & & 32 & & 30 & & $2 \cdot 20$ & $0 \cdot 78,6 \cdot 19$ & 0.13 \\
\hline Mild, moderate or no deficiency & $\geq 20$ & 37 & 22 & 69 & 15 & 56 & & & \\
\hline Severe I deficiency & $<20$ & 25 & 10 & 31 & 15 & 44 & & & \\
\hline
\end{tabular}

OR, odds ratio

Psychometric evaluation showed that children with severe I deficiency had a lower global score than children with no severe deficiency $(2 \cdot 7$ (SD 1.6) v. 3.1 (SD 1.3); $P=0.01)$.

There was no association between I deficiency and women's BMI (data not shown).

TSH concentrations were measured for 270 subjects (211 children and fifty-nine women).

Abnormal results $(>2.6 \mathrm{mU} / \mathrm{ml})$ were observed in $20.3 \%$ of the subjects. Four women (three with goitre and one without goitre) had abnormal TSH levels; this represents $6.7 \%$ of the women, whereas abnormal results were found in $24.2 \%$ of the children. Five children had very high TSH levels above 40, two children without goitre had TSH values of 81 and $206 \mathrm{mU} / \mathrm{ml}$ and three children with goitre had TSH values of 46,77 and $84 \mathrm{mU} / \mathrm{ml}$.

Data on TSH and goitre are presented in Table 4. There was a significant association between goitre and TSH. Amongst the children with goitre, $35 \%$ had abnormal TSH levels $(>2.6 \mathrm{mU} / \mathrm{ml})$ as compared with $14 \%$ of children without goitre (odds ratio $3 \cdot 10$ (95\% CI 1.6, 6.1); $P<0.001$; Table 4).

The median value of TSH was 1.12 (range $0.22-206 \cdot 00$ ) $\mathrm{mU} / \mathrm{ml}$ in the 110 children without goitre and 1.72 (range $0.06-83.60) \mathrm{mU} / \mathrm{ml}$ in the 101 children with goitre $(P<0.01)$.

No association was observed between TSH results and cognitive development.

There was a significant association between urinary I level and the rate of abnormal TSH; only one of the fourteen children with adequate urinary I had abnormal TSH, whereas $40 \%$ of the children with severe I deficiency did so $(P<0 \cdot 0006)$ (Table 5).

Urinary thiocyanate was measured in 179 children and in fifty-six women. The mean value of thiocyanate was $59.5 \mu \mathrm{mol} / \mathrm{l}$ (SD 44) in the children and $62 \mu \mathrm{mol} / \mathrm{l}$ (SD 23) in the women. There was no difference in the mean value according to the presence of goitre in either children or women. In children with no or mild I deficiency, the mean value of thiocyanate was significantly higher in the thirteen children who had a goitre $(76.7 \mu \mathrm{mol} / \mathrm{l})$ than in the thirteen who had no goitre $(53.5 \mu \mathrm{mol} / \mathrm{l})(P=0.018)$. There were too few women with no or mild I deficiency $(n 7)$ to perform the same analysis.

There was no association between thiocyanate and women's BMI.

\section{Salt evaluation}

Identification from the packaging, of the type of salt used in the households, was possible for $51 \%$ of the subjects. Only three of those were labelled 'iodised salt', with only one testing positive for I content.

\section{Discussion}

The objectives of the present study were to identify whether the presence of goitre is a satisfactory marker of I deficiency and to examine the relationship between goitre and thyroid

Table 4. Abnormal thyroid-stimulating hormone $(T S H)(\geq 2.6 \mathrm{mU} / \mathrm{ml})$ according to the presence of a goitre (Odds ratios with $95 \%$ confidence intervals)

\begin{tabular}{|c|c|c|c|c|c|c|c|c|}
\hline & \multirow[b]{2}{*}{ Total $(n)$} & \multicolumn{2}{|c|}{ No goitre } & \multicolumn{2}{|c|}{ Goitre } & \multirow[b]{2}{*}{ OR } & \multirow[b]{2}{*}{$95 \% \mathrm{Cl}$} & \multirow[b]{2}{*}{$P$} \\
\hline & & $n$ & $\%$ & $n$ & $\%$ & & & \\
\hline All & 270 & 140 & & 130 & & 2.99 & $1.52,5.63$ & 0.0004 \\
\hline $\mathrm{TSH}<2.6 \mathrm{mU} / \mathrm{ml}$ & 215 & 123 & 88 & 92 & 71 & & & \\
\hline $\mathrm{TSH} \geq 2.6 \mathrm{mU} / \mathrm{ml}$ & 55 & 17 & 12 & 38 & 29 & & & \\
\hline Children & 211 & 110 & & 101 & & 3.12 & $1 \cdot 6,6 \cdot 1$ & 0.0006 \\
\hline $\mathrm{TSH}<2.6 \mathrm{mU} / \mathrm{ml}$ & 160 & 94 & 86 & 66 & 65 & & & \\
\hline $\mathrm{TSH} \geq 2.6 \mathrm{mU} / \mathrm{ml}$ & 51 & 16 & 14 & 35 & 35 & & & \\
\hline Women & 59 & 30 & & 29 & & 3.35 & $0.33,34.4$ & NS \\
\hline $\mathrm{TSH}<2.6 \mathrm{mU} / \mathrm{ml}$ & 55 & 29 & 97 & 26 & 90 & & & \\
\hline $\mathrm{TSH} \geq 2.6 \mathrm{mU} / \mathrm{ml}$ & 4 & 1 & 3 & 3 & 10 & & & \\
\hline
\end{tabular}

OR, odds ratio. 
Table 5. Abnormal thyroid-stimulating hormone $(\mathrm{TSH})(>2.6 \mathrm{mU} / \mathrm{ml})$ in 178 children according to urinary iodine

\begin{tabular}{lcrrrrr}
\hline & & \multicolumn{4}{c}{$\begin{array}{c}\text { Abnor- } \\
\text { mal TSH }\end{array}$} \\
\cline { 5 - 6 } & Urinary I level $(\mu \mathrm{g} / \mathrm{l})$ & $n^{*}$ & $n$ & $\%$ & $P$ \\
\hline No I deficiency & 100 & 14 & 1 & 7 & $0.0006^{*}$ \\
Mild & $50-100$ & 13 & 1 & 8 & \\
Moderate & $20-50$ & 66 & 10 & 15 & \\
Severe & $<20$ & 85 & 34 & 40 & \\
\hline
\end{tabular}

${ }^{*}$ Association between urinary I level and abnormal TSH.

function (these results would help to define the criteria for targeting for I supplementation). An additional objective was to explore the consequences of I deficiency on the health of women and the mental development of children.

Because of the chosen methodology of the present study (case-control study), the prevalence of goitre in this area could not be estimated.

In planning the present study, it was anticipated that it may be difficult to find 150 children and women with goitre within the short time frame of the study. In reality, the main problem faced was in finding women and female teenagers without goitre to serve as controls. Some days, twenty-five to thirty women or girls had to be checked to find one or two without goitre to serve as controls.

This is in accordance with the results of the repeated surveys performed in this area by ACF, reporting an extremely high prevalence of visible goitre in women (50.9 and $63.7 \%$ ) (United Nations Standing Committee on Nutrition, 2002b). In August 2004, a further survey performed in the same area amongst 2226 children aged from 6 months to 15 years revealed that $17 \%$ of the screened children had a visible goitre, with a statistically significant higher prevalence in girls $(19.7 \%)$ compared with boys $(14.3 \%)$ (S. Emeriau and C. Wilkinson, unpublished results).

The present study showed that only $9 \%$ of the subjects without goitre had an adequate urinary I level $(\geq 100 \mu \mathrm{g} / \mathrm{l})$. Of the $91 \%$ with I deficiency, $8 \%$ had mild deficiency, $44 \%$ moderate deficiency and $39 \%$ had urinary I levels below $20 \mu \mathrm{g} / \mathrm{l}$. These values are much higher than the indicators set by the WHO, UNICEF, and the International Council for the Control of Iodine Deficiency Disorders to identify IDD as a public health problem. (The goal for IDD elimination is that the proportion of individuals with urinary I levels $<100 \mu \mathrm{g} / \mathrm{l}$ should be less than $50 \%$ and that less than $20 \%$ of individuals should have a urinary I level lower than $50 \mu \mathrm{g} / \mathrm{l}$ ) (World Health Organization, 1999).)

There was a statistically significant association between the presence of goitre and severe I deficiency, as measured by urinary I level; however, the difference between cases and controls was not as great as had been expected. Amongst the subjects with goitre, $52 \%$ had severe I deficiency compared with $39 \%$ of the subjects without goitre. This moderate difference between the two groups may be explained by the fact that goitre reflects chronic I deficiency in contrast to the urinary I level, which reflects acute I deficiency, without any notion of duration. Given that the majority of the subjects showed some degree of deficiency, the currently non-goitre population runs a high risk of developing goitre in the future. It is acknowledged that I deficiency is not the only possible cause of goitre and that goitrogenic substances may also be involved in the development of goitre. In the present study, the goitrogen thiocynate is not significantly associated with the observed goitre. Thiocyanate is not the unique goitrogenic substance possible in this type of very poor rural context and further study is warranted on other goitrogens which may be involved in goitre development in this particular area of Afghanistan.

Goitre is an adaptative condition that develops in response to an insufficient supply of dietary I. Adequate secretion of thyroid hormones (triiodothyronine) may be achieved through an increased trapping of iodide, as well as a preferential intrathyroidal metabolism of I, leading to a preferential synthesis of triiodothyronine. This mechanism is triggered and maintained by an increased secretion of TSH, which is responsible for the development of goitre. In adults, elevated serum TSH levels have been repeatedly but not systematically reported in chronic I deficiency (Buttfield et al. 1966; Delange et al. 1971; Fenzi et al. 1985; Delange, 1994). In the present study, only three of the twenty-nine women with goitre showed elevated TSH levels $(>2.6 \mathrm{mU} / \mathrm{l})$ compared with the paediatric population, in which one-third of the children with goitre presented with elevated TSH. Children without goitre may also have abnormal TSH levels; $14 \%$ of the children without palpable goitre fell into this category. This suggests, once again, that even if these children do not currently present with goitre, they are at risk of developing goitre later.

TSH regulation is modified according to age. TSH is widely used and accepted for measuring I deficiency in the neonate (Thilly et al. 1978; Pardede et al. 1998), but in endemic goitre areas, for a given value of thyroxine, levels of TSH are higher in the paediatric age group as compared with the adult age group. TSH measurement seems to be an appropriate marker in young children but seems to be invalid as an appropriate indicator of I deficiency amongst women (Bachtarzi \& Benmiloud, 1983; Delange, 1994).

In children, elevated TSH was also significantly associated with severe I deficiency (urinary I excretion); however, urinary I excretion seems to be the most appropriate outcome indicator for determining I deficiency (Pardede et al. 1998). Urinary I reflects an acute deficiency, and TSH level or the presence of goitre are the consequences of chronic I deficiency.

In the paediatric sample, no significant association was observed between urinary thiocyanate and the presence of goitre. Taking the subgroup of children who had no severe I deficiency into account, the mean thiocyanate level was higher in children with goitre than in children without goitre.

Urinary thiocyanate gives a measure of cyanide intake over the preceding few days, since the half-life of thiocyanate does not exceed $14 \mathrm{~d}$. Ingested cyanide from food is converted to thiocyanate, which is excreted in the urine. Thiocyanate is a goitrogen, as it inhibits the uptake of I by the thyroid gland. Cyanide intake from food consumption (such as cassava) thereby aggravates the risk of I deficiency-induced goitre (Ermans et al. 1980). This has been observed mostly if the I supply is below the recommended daily intake (Vanderpas et al. 1984). In contrast and without any clear explanation, in the present study, the thiocyanates seem to play a larger role amongst children with no severe I deficiency.

In terms of functional consequences of goitre, we could not perform accurate analysis of correlation between age, body 
size and thyroid volume, since the age data are deemed to be too inaccurate. In Afghanistan, the lack of official birth records and the years of absence of formal schooling contribute to the problem of knowing the real ages of the children.

The same difficulty applied for the cognitive development evaluation. The uncertainty of the age makes the interpretation of the tests difficult, despite the general understanding of the assigned tasks.

There was no difference in the results according to the presence of goitre, but children with severe I deficiency had a significantly lower global score than children with no severe deficiency.

A large meta-analysis examined a total of eighteen studies, in which comparisons could be made between I-deficient populations and a suitable control population, with a similar social and cultural background (Bleichrodt \& Born, 1994). These studies revealed that the mean scores for the I- and non-I-deficient groups were 13.5 intelligence quotient points apart. These data further indicate the major effect of I deficiency on neuropsychological development at a population level. Another study performed in Benin examined the effect of an improvement in I status on mental and psychomotor performance of schoolchildren (7-11 years). It was found that improvement in I status through use of iodised salt improved mental performance in this population, who were initially I deficient (van den Briel et al. 2000). I deficiency in Afghanistan should, therefore, be considered as a very important public health problem for individuals both with and without goitre, since even in subjects without goitre, less than $20 \%$ of the population have an I level $\geq 50 \mu \mathrm{g} / \mathrm{l}$, which is considered to be suboptimal or adequate.

The use of iodised salt in the prevention of I deficiency is the solution adopted by consensus. In Afghanistan, less than half of the commonly used salt is produced locally from Afghan salt mines, $45 \%$ is imported from Pakistan and 5$10 \%$ comes from Iran. Only the Iranian salt is routinely iodised and up to spring 2003, it was only available in some cities of the Western provinces (United Nations International Children's Emergency Fund, 2004).

The Afghan Ministry of Public Health and UNICEF aim to increase the availability of iodised salt to $85 \%$ of the population by assisting the establishment of salt iodisation factories in Afghanistan (Afghan Ministry of Public Health and UNICEF, 2003). At the time of the present study, however, in Gulbahar region, the household consumption of iodised salt amongst the subjects was less than $1 \%$.

Several reasons may explain this very low level of iodised salt consumption: little awareness in the population about the consequences of I deficiency, the increased cost of iodised salt, rumours about the bad taste of iodised salt in food and the lack of promotion campaigns for iodised salt.

This suggests that iodised salt consumption in the area will not increase rapidly and highlights the need for a short-term I supplementation, in the form of iodised poppy-seed oil (Lipiodol; Lazarus et al. 1992; Zimmermann et al. 2000). This supplementation should be targeted at the most vulnerable individuals (children after weaning and women of childbearing age), until the sustainable elimination of I deficiency has been proven upon objective indicators $(>90 \%$ of households using adequately iodised salt, urinary I levels of $<50 \mu \mathrm{g} / \mathrm{l}$ in less than $20 \%$ of the population and $<100 \mu \mathrm{g} / \mathrm{l}$ in less than $50 \%$ ) (World Health Organization, 1999).

The present results highlight that goitre, within this population, is clearly insufficient to determine the extent of I deficiency and hence targeting for supplementation cannot be based on the presence of goitre alone.

\section{Acknowledgements}

We thank the Afghan ACF staff who were involved in the daily collection of information, blood and urine sampling, without whom none of this would have been possible. Acknowledgements also to the ACF team for their help in designing the present study and for their advice in the field, among them Béatrice Mounier and Marc Robert. Special thanks are due to Professor F. Delange for his invaluable advice and comments.

\section{References}

Afghan Ministry of Public Health and UNICEF (2003) National Progress toward Universal Salt Iodization. In Proceedings of the Conference on Accelerating Sustained IDD Elimination, pp. 15-17. Beijing, China.

Azizi F (2001) Iodine deficiency disorders in the Middle East. IDD Newsletters 17, 33-39.

Bachtarzi H \& Benmiloud M (1983) TSH-regulation and goitrogenesis in severe iodine deficiency. Acta Endocrinol 103, 21-27.

Bellis G, Roux F \& Chaventre A (1998) Endemic cretinism in a traditional society in Mali: from the collectivity to the individual. Coll Antropol 22, 23-30.

Bernal J (2002) Action of thyroid hormone in brain. Endocrinol Invest 25, 268-288.

Bleichrodt N \& Born MP (1994) A metaanalysis of research on iodine and its relationship to cognitive development. In The Damaged Brain of Iodine Deficiency, pp. 195-200 [JB Stanbury, editor]. New York: Cognizant Communication Corporation.

Buttfield IH, Black ML, Hoffmann MJ, Mason EK, Wellby ML, Good BF \& Hetzel BS (1966) Studies of the control of thyroid function in endemic goiter in Eastern New Guinea. J Clin Endocrinol Metab 26, 1201-1207.

Delange F (1994) The disorders induced by iodine deficiency. Thyroid 4, 107-128.

Delange F, Hershman JM \& Ermans AM (1971) Relationship between the serum thyrotropin level, the prevalence of goiter and the pattern of iodine metabolism in Idjwi Island. J Clin Endocrinol Metab 33, 261-268.

Ermans AM, Mbulamoko NM, Delange F \& Ahluwalia R (1980) Role of Cassava in the Etiology of Endemic Goitre and Cretinism. Ottawa: International Development Research Centre.

Fenzi GF, Ceccarelli C, Macchia E, Rivera M, Dramaix M, Lody D, Nelson G, Delange F, Ermans AM \& Thilly CH (1985) Reciprocal changes of serum thyroglobulin and TSH in residents of a moderate endemic goitre area. Clin Endocrinol 23, 115-122.

Fierro-Benitez R, Cazar R, Stanbury JB, Rodriguez P, Garces F, Fierro-Renoy F \& Estrella E (1988) Effects on school children of prophylaxis of mothers with iodized oil in an area of iodine deficiency. J Endocrinol Invest 11, 327-335.

Hetzel BS (2000) Iodine and neuropsychological development. J Nutr 130, Suppl. 2S, 493S-495S.

Hollowell JG, LaFranchi S, Smallridge RC, Spong CY, Haddow JE \& Boyle CA (2005) 2004: Where do we go from here? - Summary of working group discussions on thyroid function and gestational outcomes. Thyroid 15, 72-76. 
International Council for the Control of Iodine Deficiency Disorders, (2004). IDD Prevalence and Control Program Data. http://indorgs. virginia.edu/iccidd/mi/idd_0.02.htm

Lazarus JH, Parkes AB, John R, N'Diaye M \& Prysor-Jones SG (1992) Endemic goitre in Senegal - thyroid function etiological factors and treatment with oral iodized oil. Acta Endocrinol 126, $149-154$

Pardede LV, Hardjowasito W, Gross R, Dillon DH, Totoprajogo OS, Yosoprawoto M, Waskito L \& Untoro J (1998) Urinary iodine excretion is the most appropriate outcome indicator for iodine deficiency at field conditions at district level. J Nutr 128, $1122-1126$.

Peterson S, Assey V, Forsberg BC, Greiner T, Kavishe FP, Mduma B, Rosling H, Sanga AB \& Gebre-Medhin M (1999) Coverage and cost of iodized oil capsule distribution in Tanzania. Health Policy Plan 14, 390-399.

Pettigrew AR \& Fell GS (1972) Simplified colorimetric determination of thiocyanate in biological fluids, and its application to investigation of the toxic amblyopias. Clin Chem 18, 996-1000.

Pharoah POD \& Connolly KJ (1987) A controlled trial of iodinated oil for the prevention of endemic cretinism: a long-term followup. Intern J Epidemiol 16, 68-73.

Plantin-Carrenard E, Cattan F, Aurengo A, Dumerat B, Foglietti MJ \& Beaudeux JL (2004) Analytical aspects of the semiquantitative determination of urinary iodine using ferroin: value of rapid screening for iodine deficiency or excess. Ann Biol Clin (Paris) 62, 456-461.

Thilly CH, Delange F, Lagasse R, Bourdoux P, Ramioul L, Berquist H \& Ermans AM (1978) Fetal hypothyroidism and maternal thyroid status in severe endemic goiter. J Clin Endocrinol Metab 47, $354-360$.
Tonglet R, Bourdoux P, Minga T \& Ermans AM (1992) Efficacy of low oral doses of iodized oil in the control of iodine deficiency in Zaire. $N$ Engl J Med 326, 236-241.

United Nations International Children's Emergency Fund (2004) 2003 Afghanistan Multiple Indicator Cluster Survey. New York: UNICEF.

United Nations Standing Committee on Nutrition (2002a) Report on the Nutrition Situation of Refugees and Displaced Populations. Refugee Nutrition Information System (RNIS), no. 38, pp. 41-49. Geneva: UNS/Standing Committee on Nutrition.

United Nations Standing Committee on Nutrition (2002b) Report on the Nutrition Situation of Refugees and Displaced Populations. Refugee Nutrition Information System (RNIS), no. 39, pp. 47-53. Geneva: UNS/Standing Committee on Nutrition.

van den Briel T, West CE, Bleichrodt N, van de Vijver FJ, Ategbo EA \& Hautvast JG (2000) Improved iodine status is associated with improved mental performance of schoolchildren in Benin. Am J Clin Nutr 72, 1179-1185.

Vanderpas J, Bourdoux P, Lagasse R, Rivera M, Dramaix M, Lody D, Nelson G, Delange F, Ermans AM \& Thilly CH (1984) Endemic infantile hypothyroidism in a severe endemic goitre area of central Africa. Clin Endocrinol 20, 327-340.

World Health Organization (1993) Global Prevalence of Iodine Deficiency Disorders. WHO/UNICEF/ICCIDD Micronutrient Deficiency Information System working paper, no. 1 Geneva: WHO.

World Health Organization (1999) Assessment of Iodine Deficiency Disorders and Monitoring of their Elimination; a Guide for Program Managers. Geneva: WHO.

Zimmermann M, Adou P, Torresani T, Zeder C \& Hurrell R (2000) Low dose oral iodized oil for control of iodine deficiency in children. Br J Nutr 84, 139-141. 